\title{
Load and No-Load Tests of the Thermoelectric Brain Cooler Designed for Brain Hypothermia
}

\author{
Abdullah Hakan YAVUZ, Raşit Ahıska
}

\begin{abstract}
A helmet was designed in this study using flexible thermoelectric modules for locally controlled cooling and heating of brain. Controller design of the cooler helmet was carried out under fuzzy logic control according to the data obtained in the previous tests on flexible thermoelectric modules used in the helmet. Test assembly was prepared for load and no load tests of the helmet in laboratory environment. A balloon with 6 liters of water was used to test the load operation of the helmet. These parameters were evaluated and discussed with respect to brain hypothermia. Power of the brain cooling system is $1.2 \mathrm{~kW}$, cooling capacity is $140 \mathrm{w}$, coefficient of performance (COP) 0.6 , load heating speed is 0.5 ${ }^{\circ} \mathrm{C} /$ minute and load cooling speed is $0.4{ }^{\circ} \mathrm{C} /$ minute. Magnetic field around the helmet was measured as $11 \mu \mathrm{T}$. Tests on the model showed that the helmet is one of the most important alternatives to cooling the brain locally, controlled heating when necessary as well as keeping it at the same temperature for long periods of time.
\end{abstract}

Keywords-Hypothermia, Brain cooler, thermolecetric

\section{Introduction}

Biologically, brain is one of the most important organs of the human body. Although weight wise it is only $2 \%$ of our body; the brain consumes $25 \%$ of the oxygen in addition to most of the glucose. $70 \%$ of human body heat is exposed in brain. Normal functioning of brain depends on an uninterrupted oxygen flow. When there is any interruption in the oxygen to brain, cells in the brain start dying rapidly thereby causing irreparable damages. As is known, oxygen transfer to the brain occurs via blood flow. Normally, cerebral circulation is controlled by several mechanisms to ensure blood flow for sufficient oxygen and food. However, in pathologic cases, parameters such as blood flow, vascular resistance and diameter are significantly out of normal limits. When cerebral circulation stops due to cardiac surgical operations or an accident, cerebral perfusion pressure drops down to values that are below normal levels which reduces the cerebral blood flow. Imbalance between energy production and consumption due to reduction of blood flow results in insufficient supply of oxygen and food to tissues.

Abdullah Hakan YAVUZ

Gaziosmanpasa University Turkey

Rasit Ahiska

Gazi University

Turkey
Rapid oxygen loss starts. Cells without oxygen start dying quickly. Cell death increases due to snowballing effect. One of the treatment methods applied to control death of cells is to cool the brain very in a very short amount of time. Death rate of strokes in clinics is less than those that occur outside the hospital. This is due to the fact that the heart and brain cells start dying within minutes. Loss of time means loss of brain. The same difficulty is valid for stroke patients as well. Brain protection is one of the most important problems in head traumas, open heart operations, strokes and cardiovascular cases [1].

Every year 1 million people suffer sudden heart failure throughout the world. Around 150.000 of them are revived. $60 \%$ of die before being discharged, $28 \%$ suffer brain damage. Only $12 \%$ of them recover without brain damage. Organizations like International Liaison Committee on Resuscitation (ILCOR), American Heart Association (AHA) and European Resuscitation Council (ERC) provide the following basic proposal in order to increase discharge rate and prevent brain damage among those who are revived: "Unconscious adult patients with spontaneous circulation as a result of sudden heart failure out of hospital with initial rhythm of ventricular fibrillation should be cooled for 12-24 hours at $32^{\circ} \mathrm{C}$ and $34^{\circ} \mathrm{C}$ ".

Such a cooling method may be useful for sudden heart failures that occur at hospitals as well as in other arrhythmias. As is known, cerebral protection is possible with hypothermia; it is provided with methods like superficial cooling (with blankets and ice packs) and lavage. But these are not sufficient and it is not possible to apply a proper heat management protocol. Temperature decrease rate is important during brain cooling. Temperature decrease needs to be homogenous. Patients should be gradually cooled with a heat gradient of less than $10{ }^{\circ} \mathrm{C}$ after hypothermia is started. It has been proven clinically that that the heart is not fibrillated until rectal $22-24{ }^{\circ} \mathrm{C}$ when slow cooling is carried out on patients. Excessive cooling rates cause excessive charging and fibrillation of the heart [2].

Cranio-Cerebral Hypothermia $(\mathrm{CCH})$ method is applied throughout the world for brain treatment and protection. Hypothermia reduces oxygen consumption and protects the brain from fatal effects of hypoxia. When human brain is cooled down to $30-32{ }^{\circ} \mathrm{C}$, it can survive without blood, oxygen and glucose. The brain can also survive for 45-60 minutes even when heart fails. When brain temperature is reduced to the desired level of $30-32{ }^{\circ} \mathrm{C}$ which is $5-7{ }^{\circ} \mathrm{C}$ less than the body temperature; it can be kept at a better condition even if the heart fails. The purpose is to limit neurologic troubles in patients during trauma or heart attack. Otherwise, survivors may suffer several neurologic damages such as problems in memory, speaking and movement. Therefore the importance of brain hypothermia is apparent and is starting to be used [3-7].

External intervention is required for undesired cases that may occur within the mechanism. The most important is 
cranio-cerebral hypothermia $(\mathrm{CCH})$ which is the direct and external cooling of the brain. In this case, cold affects the traumatic brain directly and without disrupting activities of other organs. One advantage of using cranio cerebral hypothermia in brain trauma is that this method is very simple and useful under clinic conditions as it doesn't require narcosis.

Cooling after hypothermia is one of the important subjects. Hypothermia consists of three different phases: induction, maintenance and rewarming. All of these three phases should be carried out under control. Clinic studies show that target temperatures for the first 2 phases are 32 and $34{ }^{\circ} \mathrm{C}$. Although studies related to the third phase are not much, studies on animal models after hypothermia in patients with ischemia and brain trauma after aortic surgery. Heating speed should be ideally between $0.25-0.5^{\circ} \mathrm{C}[8,9]$.

Ideal conditions for brain hypothermia are the ability to control local temperature easily and with awareness. It should also have a controlled heating property. A thermoelectric cooling device (helmet) is designed in this study consisting of thermoelectric modules to provide these conditions. Peltier modules running on peltier effect ensure formation of cold and hot surfaces by providing heat flow between the junctions of the material of two different types. This quality puts them forward for hypothermia. Current and voltage is changed easily for conscious adjustment of hot and cold side temperatures. Laboratory tests were carried out for the helmet which has been developed to provide brain hypothermia after which the acquired results were evaluated.

\section{Material and Method}

\section{A. Material}

Thermoelectric devices are designed by using thermoelectric modules consisting of thermo elements. Thermoelements are made up of serially connected $n$ (negative) and p (positive) type semi-conductors. These are positive and negative arms of thermoelements. Thermoelements are serially connected to form a module. Figure 1 shows a thermoelectric module structure consisting of thermoelements. When designing a thermoelectric device, all parameters of modules should be calculated beforehand hence the module should be selected according to the device to be designed.

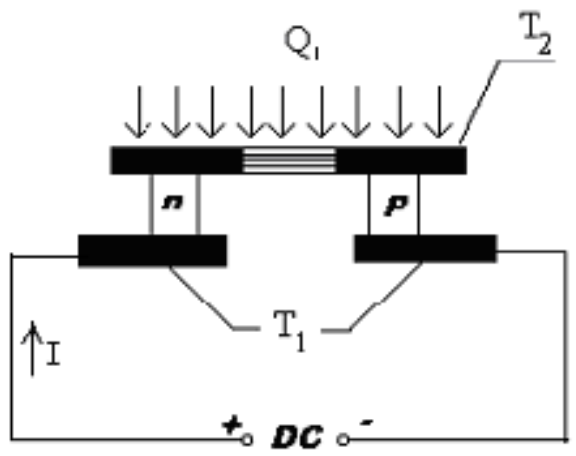

Figure 1. Structure of thermoelectric module
A new method has been developed which evaluates all running parameters of thermoelectric modules. The new method developed by R. Ahiska is based on current (I), voltage on ends $(\mathrm{V})$, thermoelectric generated $(\mathrm{E})$ and measurement of temperature value on any surface $\left(\mathrm{T}_{\mathrm{H}}\right.$ or $\mathrm{T}_{\mathrm{C}}$ ). Total effects of all internal and external factors affecting the performance of TE (thermoelectric) modules are taken into consideration automatically by the new method based on the use of $\mathrm{V}_{\max }, \mathrm{I}_{\max }$ and $\mathrm{E}_{\max }$ parameters of the module as these parameters are obtained via direct measurement of the operating module.

For non-load TE module, total thermal load $\mathrm{Q}_{\mathrm{L}}=0$ while cold energy quantity generated in unit time is $\mathrm{Q}_{\mathrm{C}}=0$. In this case, temperature of cold surface is $\mathrm{T}_{\mathrm{Cmin}}$, temperature difference between surfaces is $\Delta \mathrm{T}_{\max }$. In addition, the current of TE module is expressed as $\mathrm{I}_{\max }$, voltage as Vmax and the generated thermoelectric as $E_{\max }$. The equations obtained by the new method developed are shown in Equation 1 [10-17].

Electrical resistance $(\mathrm{R})$ of TE module as ohm is ;

$$
R=\frac{V_{\max }-E_{\max }}{I_{\max }}
$$

Thermal conductivity coefficient $(\mathrm{K})$ value of TE module as W.K-1;

$$
K=\frac{0.5 V_{\max }\left(V_{\max }-E_{\max }\right) I_{\max }}{T_{H} E_{\max }}
$$

Total heat load $\left(\mathrm{Q}_{\mathrm{C}}\right)$ to the cold surface of TE module as watt;

$$
Q_{C}=V_{\max } I-\frac{0.5 I^{2}\left(V_{\max }-E_{\max }\right)}{I_{\max }}-\left[I+\frac{0.5\left(V_{\max }-E_{\max }\right) I_{\max }}{E_{\max }}\right] E
$$

Total heat $\left(\mathrm{Q}_{\mathrm{H}}\right)$ exposed on the surface of TE module as watt;

$Q_{H}=V_{\max } I+\frac{0.5 I^{2}\left(V_{\max }-E_{\max }\right)}{I_{\max }}-\frac{0.5\left(V_{\max }-E_{\max }\right) I_{\max } E}{E_{\max }}$

Power $(\mathrm{P})$ consumed by TE module as watt;

$$
P=\frac{I^{2}\left(V_{\max }-E_{\max }\right)}{I_{\max }}+E I
$$
(COP);

Efficiency of TE module that is performance coefficient

$$
C O P=\frac{Q_{C}}{P}=\frac{V_{\max } I-\frac{0.5 I^{2}\left(V_{\max }-E_{\max }\right)}{I_{\max }}-\left[I+\frac{0.5\left(V_{\max }-E_{\max }\right) I_{\max }}{E_{\max }}\right] E}{\frac{I^{2}\left(V_{\max }-E_{\max }\right)}{I_{\max }}+E I}
$$

TE module quality coefficient ( $\mathrm{Z}$ - Figure of Merit) value as $\mathrm{K}-1$; 


$$
Z=\frac{V_{\max } E_{\max }}{0.5\left(V_{\max }-E_{\max }\right)^{2} T_{H}}
$$

Temperature value $\left(\mathrm{T}_{\mathrm{C}}\right)$ on the cold surface of $\mathrm{TE}$ module as $\mathrm{K}$;

$$
T_{C}=T_{H}\left(1-\frac{E}{V_{\max }}\right)
$$

Temperature value $\left(\mathrm{T}_{\mathrm{H}}\right)$ on the surface value of $\mathrm{TE}$ module as $\mathrm{K}$;

$$
T_{H}=\frac{T_{C}}{\left(1-\frac{E}{V_{\max }}\right)}
$$

Thermoemk (E) value of TE module as volt;

$$
E=V_{\max }\left(1-\frac{T_{C}}{T_{H}}\right)
$$

In order to use Equation 1, both Imax, $V \max$ and $\mathrm{E}_{\max }$ experimental parameter values and one of the $T_{C}$ or $T_{H}$ temperatures should be directly measured. According to these formulas, instead of parameters of TE semiconductors used in the classical method like $\mathrm{K}$ thermal conductivity, $\alpha$ Seebeck coefficient, $\rho$ resistivity, experimental parameters like $I_{\max }, V_{\max }$ and $E_{\max }$ have been used. It is sufficient to use $\mathrm{V}_{\max }=2 \cdot \mathrm{N} \cdot \alpha \cdot \mathrm{T}_{\mathrm{H}}$ as well as Equation 1 to switch from formulas in the new methods to classical formulas [10-17].

Here Vmax and $E_{\max }$ characterize TE semiconductors consisting of TE module, therefore these parameters are not bound to geometrical qualities of semiconductors and do not constitute the macro sizes of the module. The obtained equations characterize the parameters of a real module. In addition, these equations can also be evaluated as an indicator of the quality of structural methods and material used in the production of TE module and systems [10-17].

Devices made of thermoelectric modules are commonly used in medical applications. Medical material like blood, serum, drugs should be kept under certain temperature conditions in order to store without decay. There are portable medical kits developed for this purpose [18-21]. Thermoelectric cooling or heating is used in therapeutic pads used for treatment or pain relieving. Pad temperature is adjusted by passing water through liquid coolers consisting of solid based modules. Here, thermoelectric modules are used to cool or heat water. Another example of thermoelectric systems in the field of medicine is the application of renal hypothermia [22].

Millions of dollars are spent for hypothermia research throughout the world. Hundreds of researchers work in the research and development departments of universities. Rats are wholly submersed in water to cool their brain for brain hypothermia and heating is carried out via lamp beam [23, 24]. Rat thermo hypothermia is developed to cool the brain of rats through thermoelectric method [25].

Several designs in the shape of thermoelectric helmets can be found in global patent search. When these designs are examined, Figure 2 shows that they are designed by using solid based modules [26-28].
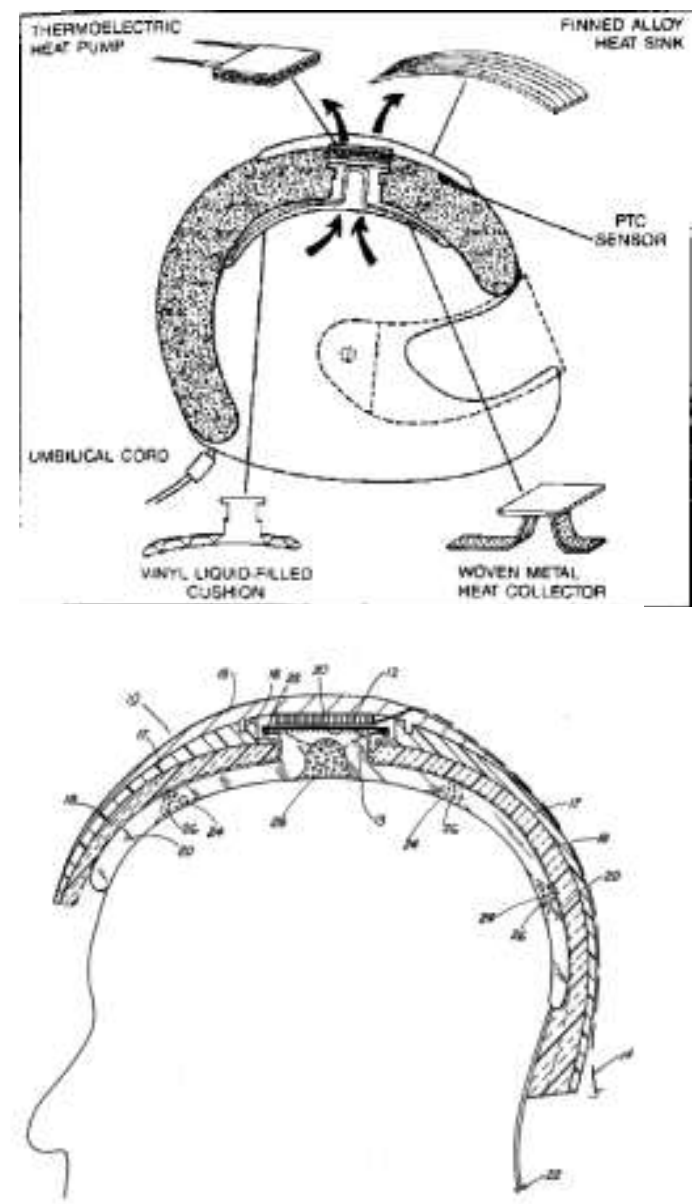

Figure 2. Various helmet designs

Modules generated in the market are solid based modules. Designing helmets with these modules is very difficult. The most important element in brain cooling is the homogenous cooling of the brain. Modules should have high number of contact surfaces with the head. These solid based modules of $4 \times 4 \mathrm{~cm}$ impose restrictions on contact surfaces. Producing module dimensions to increase contact surfaces reduces the power of modules due to which required cooling cannot be provided. Therefore, there are restrictions in its use. Obtaining flexible thermoelectric modules instead of solid based modules is a development to remove this problem. Contact surface can be increased without reducing cooling performance of module by using flexible thermoelectric modules. There is no restriction in current.

In this study, thermoelectric helmet was obtained by providing serial electrical connection and parallel thermal connection as is shown in Figure 3. Figure 4 indicates a helmet designed by using 70 thermoelectric modules. The helmet is divided into two parts: right and left. There are equal numbers of modules in both parts. Modules used are specifically produced modules. 0.1 volt and maximum 40 ampere are required to drive each module. Modules are produced flexibly as shown in figure 3 . Therefore, flexible joint increased the solidity and guaranteed operation time of modules. The most important advantage of the use of flexible thermoelectric modules in medicine is the ability to form it to the shape of the area to be cooled. Water 
temperature is air conditioned by a separate cooling system and circulated in the external part of the helmet through a water circulation system.

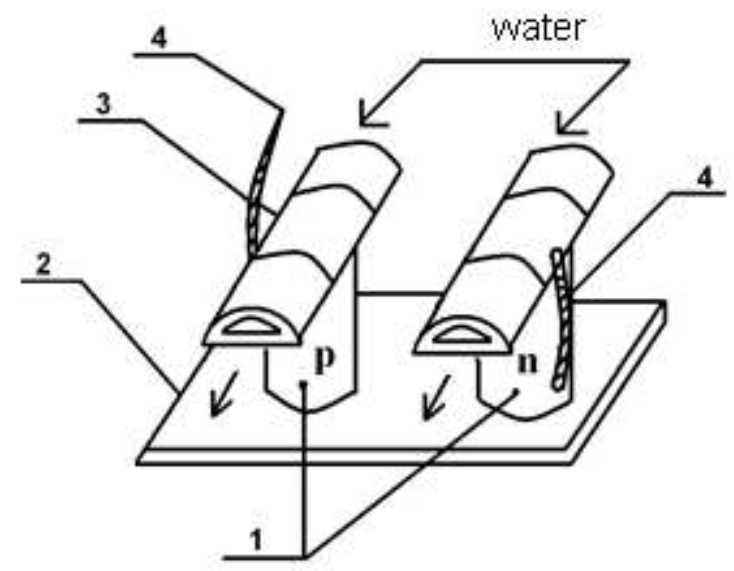

Figure 3. Structure of the flexible thermoelectric module used in helmet design

Here, 1 shows $\mathrm{p}$ and $\mathrm{n}$ type semi inductors, 2 shows cold surfaces of copper plate modules, 3 shows hot surfaces of copper pipes, 4 shows multiple wire copper cable for the voltage input of the module.
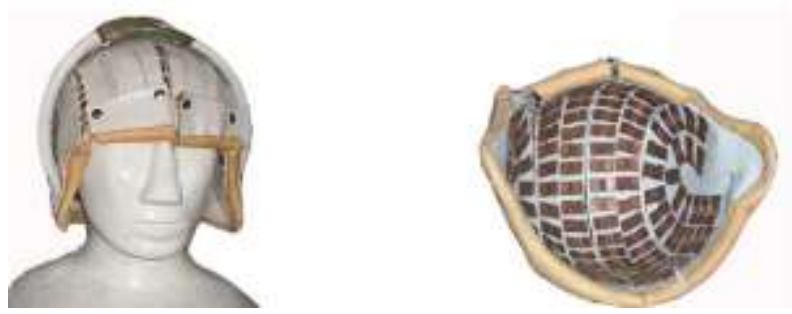

Figure 4. Thermoelectric helmet

\section{B. Method}

Fuzzy method was used for system control. Helmet was designed in 2 parts. Parts can be controlled both independently and together. A total of 8 thermocouples were placed for both sides of the helmet; 4 each from K type into the internal surface. Measured values from the thermocouple were transmitted to the computer via RS232 port. Another bridge circuit was designed by using 1 driver and IGBT for both sides of the helmet. PIC18F4520 microcontroller was used in the control circuit designed to transfer to and from computer. This circuit also generates PWM signals of the driver circuits used to adjust current. Figure 5 includes the block diagram of the system.

Thermoelectric helmet can control right and left sections together or separately. In experimental installation, right and left parts were operated by entering the same control parameters. System stability was tested by repeating the same control parameters several times with the same control parameters. Reactions of the system to load and no-load operations were evaluated.

\section{Experimental Setup}

A model was created to conduct load and no load tests of the designed system. No load tests were performed when the helmet was empty. Based on the fact that $78 \%$ of the brain consists of water in the load model; a balloon was filled with 6 liters of water and placed in the helmet. A stick with fixed thermocouples at $5 \mathrm{~cm}$ intervals was placed in the balloon. One of the thermocouples shows the temperature on the surface whereas the other displays the temperature at a depth of $5 \mathrm{~cm}$. This distance was chosen as the hypophysis and thermoregulation center was located at a depth of about 5 $\mathrm{cm}$ from the surface. Fluke 52 digital thermometer with double thermocouples was used to measure these temperatures.

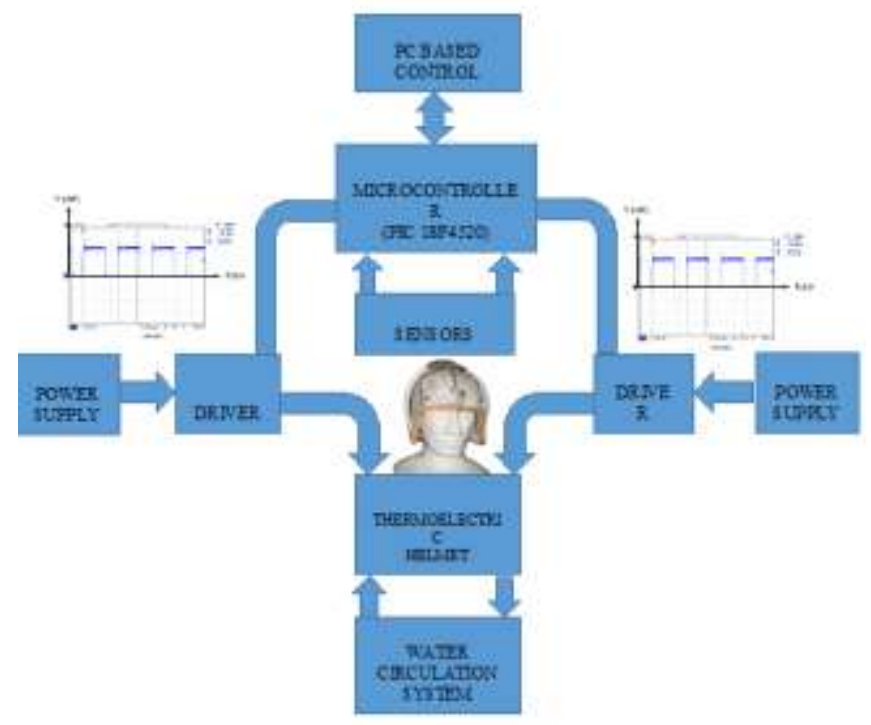

Figure 5. Block diagram of the designed system

In the first application, the system was operated in the heating and cooling mode before placing the balloon into the helmet. In the second application, the balloon was placed into the helmet. The helmet was operated in cooling mode and values were recorded. In the third application, the helmet was operated in heating mode and values were recorded. During these measurements, a wattmeter was connected to the input to calculate the power drawn. Right and left parts of the helmet were controlled as a whole for all of the three applications. However, different control parameters can be entered by using the software for the left and right parts of the helmet. Threshold values are available for system control. Limit values can be entered via the software for the cold part and hot part ensuring that the system automatically cuts the current and voltage to the helmet if these values are exceeded. If the system returns to normal, it continues with the same control parameters. This can be reported.

Figure 6 shows the test assembly prepared for no load operation. As shown, the inside of the helmet was left empty.

Figure 7 shows the test assembly prepared for the load operation tests. As shown by the figure 7, a plastic balloon filled by water was placed into the helmet and two thermocouples in $5 \mathrm{~cm}$ distance on a stick were placed into the balloon. 
Proc. of The Fifth Intl. Conf. On Advances in Applied Science and Environmental Technology - ASET 2016 Copyright (C) Institute of Research Engineers and Doctors, USA .All rights reserved.

ISBN: 978-1-63248-106-1 doi: 10.15224/ 978-1-63248-106-1-36

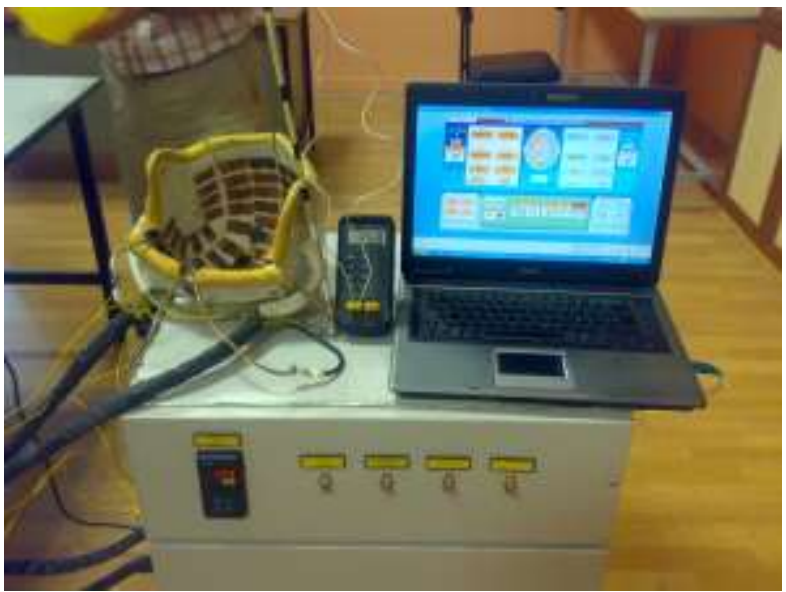

Figure 6. No load test assembly of brain cooler

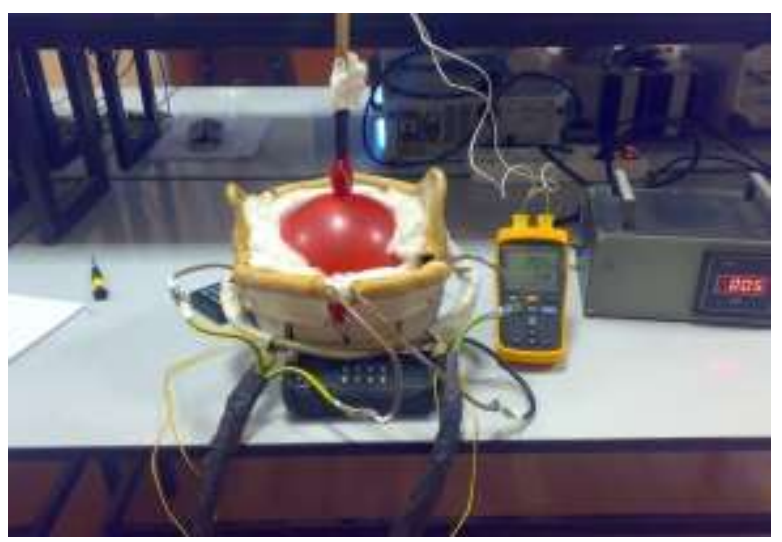

Figure 7. Brain cooler load test assembly

\section{Iv. Finding and discussion}

Temperature differences, heating and cooling speeds when the helmet is operated with no load in the first application, time based $\mathrm{T}_{\mathrm{H}}, \mathrm{T}_{\mathrm{C}}, \Delta \mathrm{T}$ graphs were drawn separately for the right and left parts. These graphs are as shown in Figure 8-9.

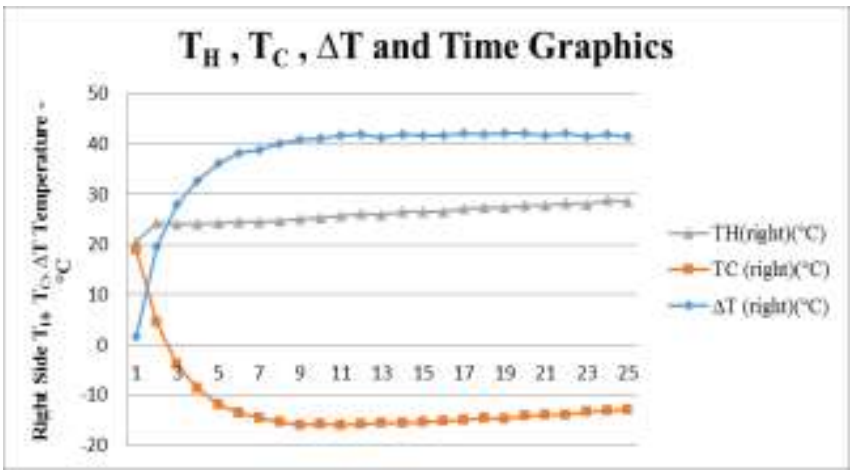

Figure 8 . Right side temperature values of the helmet

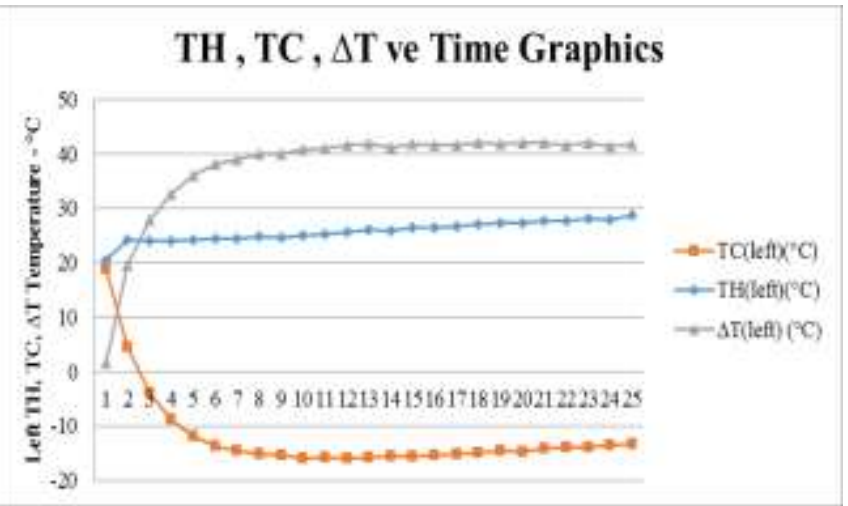

Figure 9. Left side temperature values of the helmet

According to the data obtained as a result of the first application, no load helmet's cooling speed $=$ temperature difference / time and it were calculated as $0.5^{\circ} \mathrm{C} /$ minute. With a speed of $0.5{ }^{\circ} \mathrm{C} /$ minute, temperatures reduced from $20{ }^{\circ} \mathrm{C}$ to $-13{ }^{\circ} \mathrm{C}$. Total power drawn by thermoelectric helmet was measured as 243 watt.

In the second application, the balloon was placed into the helmet and right and left sides of the helmet were operated with full cooling capacity and $\mathrm{T}_{\mathrm{C}}, \mathrm{T}_{\mathrm{H}}$, current, voltage, $\Delta \mathrm{T}$ values of right and left sides were recorded into the data base by computer software. Temperatures of thermocouples placed in the balloon at $5 \mathrm{~cm}$ intervals were recorded by taking readings every 1 minute. Figure 10 shows the graphs of the data obtained.

According to the data obtained as a result of the second application, the cooling speed of the loaded helmet was calculated as $0.4{ }^{\circ} \mathrm{C} /$ minute. Water temperature in the balloon reduced rapidly from $20{ }^{\circ} \mathrm{C}$ to $3{ }^{\circ} \mathrm{C}$ at a speed of 0.4 ${ }^{\circ} \mathrm{C} /$ minute. Total power drawn by the thermoelectric helmet was measured as 240 watt.

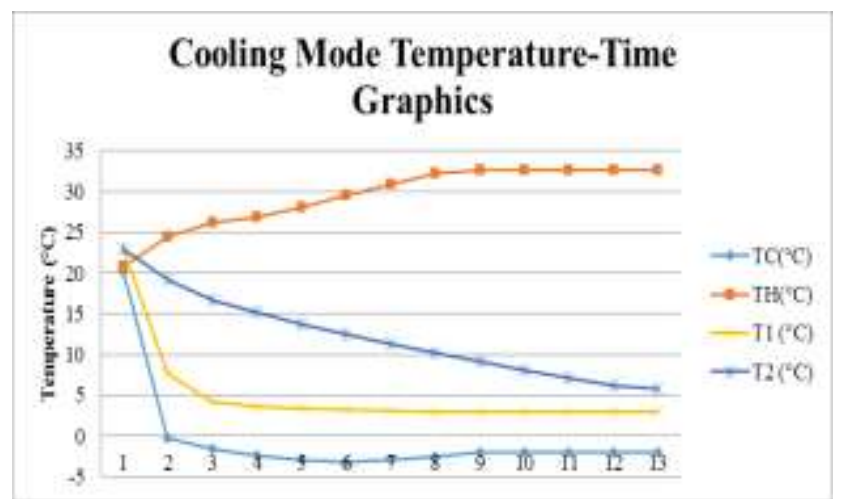

Figure 10. Load operation cooling mode temperature-time graphics

Third application involved operation of the helmet at full heating capacity. Figure 11 shows the graphs of the data obtained. 
Proc. of The Fifth Intl. Conf. On Advances in Applied Science and Environmental Technology - ASET 2016 Copyright $@$ Institute of Research Engineers and Doctors, USA .All rights reserved.

ISBN: 978-1-63248-106-1 doi: 10.15224/ 978-1-63248-106-1-36

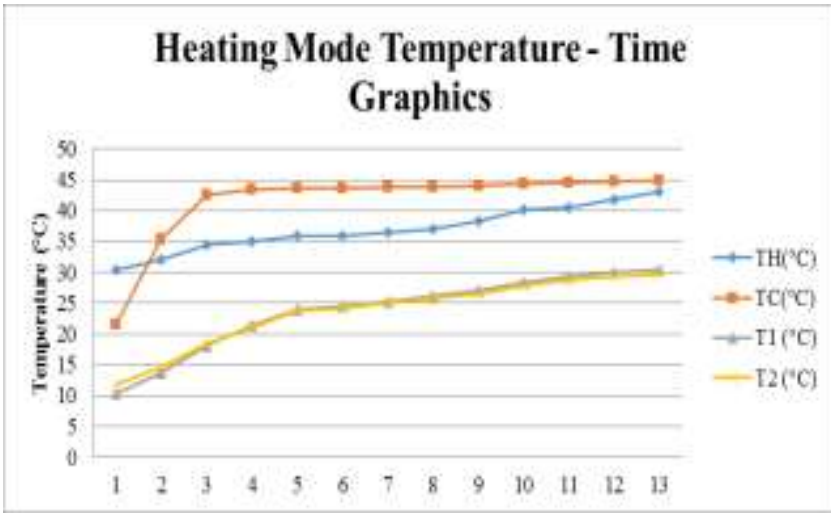

Figure 11. Load operation heating mode temperature-time graphics

According to the information obtained as a result of the third application, heating speed of the loaded helmet was calculated around $0.3{ }^{\circ} \mathrm{C} /$ minute. The temperature of the water in the balloon was increased from $10{ }^{\circ} \mathrm{C}$ to $30{ }^{\circ} \mathrm{C}$ at a speed of $0.3{ }^{\circ} \mathrm{C} /$ minute. Total power drawn by the thermoelectric helmet was measured as 240 watt.

Thermoelectric qualities were obtained by evaluating the speed as a single piece. For the 6 liter water in the helmet, mass is $\mathrm{m}=6 \mathrm{~kg}$, specific heat of water $\mathrm{C}=4180 \mathrm{j} / \mathrm{kg} .{ }^{\circ} \mathrm{C}$, $\Delta \mathrm{T}=20{ }^{\circ} \mathrm{C}$ temperature difference takes place in 1 hour $=3600$ seconds and the thermal power absorbed by the helmet can be calculated in watt by the formula $\mathrm{Q}_{C}=$ C.m. $\Delta \mathrm{T} / \mathrm{t}$. The cooling capacity of the helmet is found to be around $\mathrm{Q}_{\mathrm{C}}=140 \mathrm{~W}$ according to this formula. Since the power drawn by the helmet is $\mathrm{P}=240 \mathrm{~W}$, the yield of the helmet was calculated as $\mathrm{COP}=\mathrm{Q}_{\mathrm{C}} / \mathrm{P}=140 / 240=0.6$. Therefore, the cooling capacity of the helmet is $140 \mathrm{~W}$, yield is $60 \%$.

In addition, magnetic fields inside and outside the helmet and on the cables were determined. These measurements were carried out via the Lutron EMF-323 model measurement device. Values are shown in Table 1.

Table 1. Magnetic field values of the thermoelectric helmet

\begin{tabular}{|c|c|}
\hline Inside helmet & $10.5-11.2 \mu \mathrm{T}$ \\
\hline Outside helmet & $10.5-17.5 \mu \mathrm{T}$ \\
\hline Cables & $60 \mu \mathrm{T}$ \\
\hline
\end{tabular}

Specific absorption rate (SAR) is defined as the measurement of the interaction of the electromagnetic radiation created by systems with the live tissue. SAR is related to the power absorbed or transformed to heat. In order to define the limits that cause damage to human health, "basic limits" and "derived limits" were defined. As a basic limit in standards, $4 \mathrm{~W} / \mathrm{kg}$ value was accepted as the limit value based on the definition that "absorption of electromagnetic energy to increase the body temperature in human body one degree in average is harmful". SAR limit for the head area of people is $2 \mathrm{~W} / \mathrm{kg}$ in European countries and $1.6 \mathrm{~W} / \mathrm{kg}$ in America. When the magnetic area value within the helmet is evaluated according to these restrictions and considering the $640 \mu \mathrm{T}$ value determined by TSE, it was observed that the values are well below dangerous limits.

The results of this study show that, helmets designed with flexible thermoelectric modules are one of the most important alternatives for brain hypothermia with local cooling. In our model application, model temperature can be reduced to desired temperature values with $0.4{ }^{\circ} \mathrm{C}$ per minute. When the temperatures on the surface as well as at a depth of $5 \mathrm{~cm}$ are taken into consideration; the difference was measured to be $2.8^{\circ} \mathrm{C}$. Studies in recent years focus on fast brain cooling, keeping the brain at constant temperature as well as slow heating. When an evaluation is made with respect to three phases of hypothermia: Temperature reduction speed during brain cooling is important. Temperature reduction needs to be homogenous. Patients should be cooled slowly with a heat gradient less than $10^{\circ} \mathrm{C}$ after starting hypothermia. Otherwise, heart suffers fibrillation. Cooling and heating speed of thermoelectric helmets can be adjusted. That is, cooling or heating speed per minute can be entered into the system as a degree parameter. It can be kept any time at this temperature. These qualities reveal the most important advantages of thermoelectric helmets for the first two phase of hypothermia.

When the third phase of hypothermia is considered, "rewarming" is very important; that is bringing the temperature back to its previous level after hypothermia is over. Relevant studies are increasing in recent years. Heating process can also be adjusted in our study. In heating model application, heating speed was calculated as $0.3{ }^{\circ} \mathrm{C}$. Having an adjustable heating speed eliminates the risk of negative effects on some parameters like intracranial pressure that may occur due to uncontrolled heating. Studies show that rewarming speed should be between $0.25-0.5{ }^{\circ} \mathrm{C}$. It is possible to reach these speeds by using thermoelectric helmet.

\section{v. Conclusion}

Power drawn by the brain cooling system is $1.2 \mathrm{~kW}$ while the cooling capacity is $140 \mathrm{~W}$. Performance coefficients COP is around 0.6 and cooling and heating speed control is $0.5{ }^{\circ} \mathrm{C} /$ minute. Magnetic field around the helmet is around $11 \mu \mathrm{T}$. System runs with fuzzy logic method and special software has been developed in Visual Basic programming language to run the system.

Model application showed that the model temperature can be reduced at a desired rate, down to desired levels and within the desired periods of time. The same process can be carried out for the heating mode as well. Selective brain hypothermia can also be used on humans by using these materials and methods. Since it is suitable for clinical conditions, it can be used for patients with brain trauma or resuscitated patients after cardiac arrest as seen in cerebral ischemic cases. It is also a convenient method and technique for therapeutic hypothermia applications.

\section{References}

[1] LIU J. Cooling Strategies and Transport Theories for Brain Hypothermia Resuscitation. Energy Power Eng. 2008, 1(1), 32-57.

[2] Büket, S., Özbaran, M., Alayunt, A. Aort cerrahisinde derin hipotermik total sirkulatuvar arrest uygulamas1. Türk Göğüs Kalp Damar Cerrahisi Dergisi, 1994, 2(1): 91-94.

[3] Ovul, I., Nadirzade, R.S., Oner, K., Nadirzade, S.M. A method for monitoring intracerebral temperature in neurosurgical patients. Technology-Surgical Approaches 1997, 3(2): 354. 
[4] Ovul, I., Nadirzade, R.S., Oner, K., Nadirzade, S.M. A new technique for brain hypothermia. Technology-Surgical Approaches 1997, 3(3):353.

[5] Ahıska, R., Güler, İ., Kaymaz, M., Yavuz, A.H. Control of a thermoelectric brain cooler by adaptive neuro-fuzzy inference system. Instrumentation Science and Technology 2008, 36(3): 636-655.

[6] Ahıska, R., Güler, İ, Yavuz, A. H., Toprak, A. Neuro-Fuzzy Inference System For Control Of A Thermoelectric Brain Cooler. Journal of Thermoelectricity 2008, 4(2): 64-70.

[7] Steven, B., Michael, D., Darwin, G., Sandra, R. Rapid $\left(0.5^{\circ} \mathrm{C} / \mathrm{min}\right)$ minimally invasive induction of hypothermia using cold perfluorochemical lung lavage in dogs. Journal of Resuscitation 2001, 50(3): 189-204

[8] Bernard SA, Gray TW, Buist MD, et al. Treatment of camotose survivors of out-of-hospital cardiac arrest with induced hypothermia. N Engl J Med 2002, 346:557-63.

[9] Nikolay M., Mild therapeutic hypothermia to improve the neurologic outcome after cardiac arrest. N Engl J Med 2002, 346:549-56.

[10] Ahıska R, and Ahıska, K. New method for investigation of parameters of real thermoelectric modules Energy Conversion and Management 2010, 51: 338-345.

[11] Ahiska R. Comparing analysis of a new method for measurement of parameters of real thermoelectric modules. In: XIII international forum on thermoelectricity, 10-13 February, Kiev, Ukrayna; 2009. p. $28-36$

[12] Ahıska R, Ahıska, G and Ahıska, K. Analysis of a new method for measurement of parameters of real thermoelectric module employed in medical cooler for renal hypothermia. Inst. Sci. \& Tech. 37:102123.

[13] Ahıska R. New method for studying parameters of a thermopile Journal of Thermoelectricity 2009, 3: 71-80.

[14] Ahiska R. et al. A new test method and system for the measurement of Z-parameter of standard peltier modules. J. Fac. Eng. Arch. Gazi Univ. 2004, 19: 467-473.

[15] Ahıska R.The study of thermoemf effect on exit parameters of thermoelectric modules International Conference "Fizika - 2005" Baku Azerbaijan 2005, 33: 144-148.

[16] Ahıska R. New method for investigation of dynamic parameters of thermoelectric modules. Turk J Elec Engin TUBITAK 2005, 15: 5165 .

[17] Ahıska R. New method for study dynamic exit properties of thermoelectric modules. J. Fac. Eng. Arch. Gazi Univ. 2007, 22: 709716.

[18] Güler, N.F., Ahıska, R. Design and testing of a microprocessorcontrolled portable thermoelectric medical cooling kit. Applied Thermal Engineering, 2002, 22(1): 1271-1276.

[19] Shields, C.E., McPeak, D.W., Rothwell, J.C. Investigation of materials and methods for air delivery of whole blood and blood products. Military Medicine. 1968, 133(3): 614-621.

[20] Haynes, D.H., Monaghan, W.P. Blood storage and transport in the field using a portable thermoelectric refrigerator: assessment of potential use. Military Medicine, 1984, 149(3): 184-188.

[21] Standards for Blood Banks and Transfusion Services, 11th ed., "Prepared by the Committee on Standards", American Association of Blood Banks, Washington, DC (1984).

[22] Ahıska, R., Ahıska, G., Ahıska, K. Analysis of a new method for measurement of parameters of real thermoelectric module employed in medical cooler for renal hypothermia. Instrumentation Science and Technology $2009,37(1): 102-123$.

[23] Clifton, G.L. Hypothermia and severe brain injury. Journal of Neurosurgery 2000, 93(4): 718-719.

[24] Clifton, G.L., Steven. A., Berry, J., Koch, S., M. Systemic hypothermia in treatment of brain injury. Journal of Neurotrom 1992, 9(2): 487-495.

[25] Ahıska, R., Demirel, H., and Erkal, B. Post traumatic protection of brain in rats using rat termohypotherm device. Journal of Science 2004, 17(4): 29-38

[26] Walter, Henry j., Patent, European Patent, A61, F7/00, 07.09.1978.

[27] Kramer, Robert W., Patent, European Patent, A61, F7/00, 25.03.1985.

[28] Ahiska, R., Patent, EP, A61, F7/00, 18 October, 1993.
About Author (s)

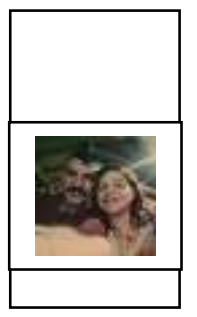

Hakan YAVUZ was born at 1975 in

Tokat/Turkey. He is working Asst.Prof. at Gaziosmanpasa University. 